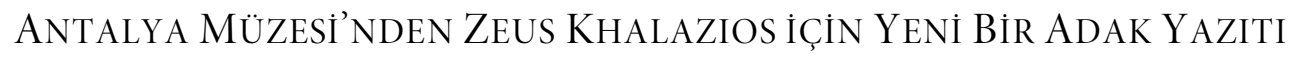

A NEW VOTIVE INSCRIPTION TO ZEUS CHALAZIOS FROM THE ANTALYA MUSEUM

\title{
NURAY GÖKALP ÖZDİL*
}

Öz: Makalede Antalya Müzesi’nde yer alan yeni bir yazıt tanitılmaktadır. Buluntu yeri belli olmayan stel, bir adak taşı niteliğindedir. Yazıtından anlaşıldığı üzere, Dēmētrios adında bir rahip Zeus Khalazios için masraflarını kendi parasından karşlamak suretiyle bir adak diktirmiştir. Khalazios sıfatı Hellence'de dolu yağmak fiilinden türetilmiştir. Dolayısıyla bu epitheton şiddetli yağmur ve dolu gibi doğa olaylarıyla bağlantılı görünmektedir. Stelin iki yan yüzünde Zeus'la bağlantılı unsurlar yer almaktadır. Sağ yüzünde üzüm salkımı, sol yan yüzünde ise şimşek demeti işlenmiştir. Şimşek demeti hava olaylarıyla ilgilidir, üzüm salkımı ise bereketi simgelemektedir. Dolayısıyla yağışların, toprağın verimiyle doğrudan ilgisi bulunmaktadır. Daha önce Mysia ve Kilikia bölgelerinde belgelenen bu epitheton Antalya Bölgesi'nde ilk defa görülmektedir. Günümüzde tarımsal üretime yön veren Antalya Bölgesi, antikçağda da oldukça verimli bir bölgeydi. Makalede khalazios sıfatının içeriğinden hareket ederek bölge tarımına ve aynı zamanda ekonomisine ilişkin epigrafik verilere değinilmektedir. Yazıt MS. II.-III. yüzyıllara tarihlendirilmektedir ve buluntu yeri aynı zamanda yazıtta zikredilen isimlere göre anlaşılmaya çalışılmaktadır.

Anahtar Kelimeler: Antalya Müzesi • Adak Yazıtları • Zeus • Khalazios • Kült • Hellence İsimler
Abstract: In this article, a new votive inscription from the Antalya Museum is presented. The inscription is of votive character and the provenance of the dedication is unknown. It is understood from the inscription that the priest Dèmètrios erected the stele to Zeus Chalazios at his own expence. The adjective khalazios derives from the verb hail in Ancient Greek. Therefore, this epithet appears to be directly related to weather events such as heavy rain and hail. There are symbols associated with Zeus on both sides of the stele. The bunch of grapes was engraved on the right and a thunderbolt was engraved on the left side of the stele. The thunderbolt denotes weather phenomena and the grape-bunch denotes agriculture and fertility. Therefore, precipitation is directly related to the yield of the soil. This epithet, previously attested in Mysia and Cilicia regions, has hitherto been unattested in Antalya Region. In the article, the epigraphic data regarding economy and agriculture of the region is referred based on the content of the epithet. As the provenance of the inscription is unknown, the findspot of it has been discussed by the author according to the spreading area of the names.

Keywords: Antalya Museum - Votive Inscriptions • Zeus • Chalazios • Cult • Greek Personal Names

Makaleye konu olan stel Antalya Müzesi’nde etütlük eser kapsamındadır ve 2018 yılı çalışmaları sırasında tarafımdan kaydedilmiştir. Geliş yeri ve zamanı bilinmeyen eserin envanter numarası 2020/26'dır. Dikdörtgen prizma şeklindeki kalker stelin yüksekliği 1.49 metre, genişliği gövdede 0.53 metre ve derinliği 0.49 metredir. Taşın ön ve sol yan yüzündeki izler, arazi çalışmaları esnasında kepçenin denk gelerek taşı aşındırdığını düşündürmektedir. Stel, palmet motifli köşe akroterlerine sahiptir, bu akroterler tamdır. Taşın üst kısmı düzleştirilmiştir ve akroterler arası silindirik bir form haline getirilmiştir. Stelin ön yüzünde merkezi konumda duran bir Zeus büstü bulunmaktadır. Cepheden işlenmiş büst göğüs hizasındadır ve mantoludur. Saçları kabarık ve dalgalı, sakalı ise gür ve bukleli işlenmiştir. Büstün yüksekliği 0.35 metre, genişliği ise 0.31 metredir. Stel gövdesi

* Doç. Dr., Akdeniz Üniversitesi, Edebiyat Fakültesi, Eskiçağ Dilleri ve Kültürleri Bölümü, Antalya.

(ㄱ)0000-0001-7611-8732 | gokalp@akdeniz.edu.tr

Çalışma izni ve yardımları için öncelikle Antalya Müzesi Müdürlüğü’ne, sonra da başta Arkeolog-Restoratör F. Nur Direr Konukman olmak üzere Arkeoloji Bölümü’ndeki tüm araştırmacılara teșekkür ederim. 
yüksekliği ise 0.60 metredir. Ölçüler, bu büstün stel gövdesinin yarısını kapladığını göstermektedir. Stelin diğer yüzleri de işlenmiștir. Sağ yan yüzde şimşek demeti, sol yan yüzde oldukça aşınmış bir üzüm salkımı, arka geniş yüzde ise bir çelenk görülmektedir. Büstün altında beş satırdan oluşan bir yazıt yer almaktadır. Yazıtın harf yüksekliği 0.03 metredir ve harfler iyi okunabilmektedir. Fakat taşın gözenekli yapısı nedeniyle yer yer aşınmalar görülmektedir. Stel tabanında sağ tarafta kırıklar ve aşınmalar mevcuttur.

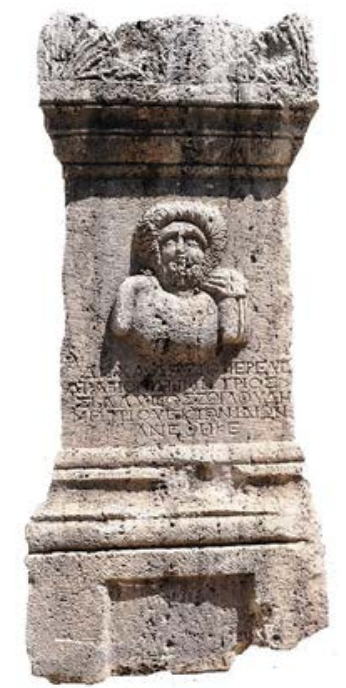

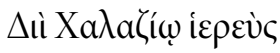

2

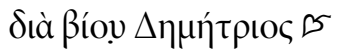

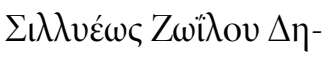

$4 \quad \mu \eta \tau \rho i ́ o v ~ \varepsilon ̇ \kappa \tau \tilde{\omega} v i ̉ \delta i ́ \omega v$

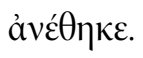
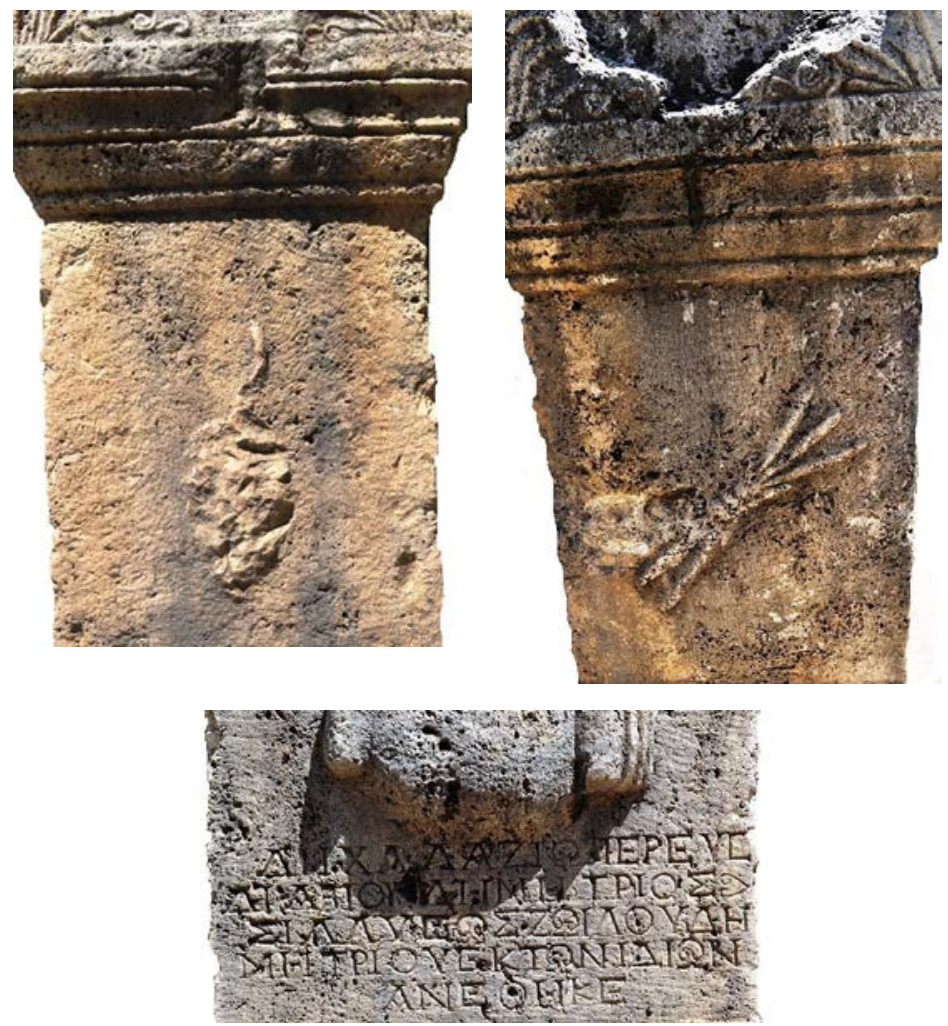

Çeviri: "Dēmētrios oğlu Zōilos oğlu Sillyeus oğlu yaşam boyu rahip olan Dēmētrios, Zeus

Khalazios için masrafların kendisi karşılamak suretiyle (bu adağı) dikti”.

Tarih: Yazıtının harf karakteri ve figürün tipolojik özellikleri MS. II.-III. yüzyıla tarihlenebileceğini düşündürmektedir.

Yazıttan anlaşıldığı üzere Dēmētrios adında bir rahip, steli Zeus Khalazios için maliyetini üstlenerek diktirmiştir. Khalazios epitheton'u Antalya Bölgesỉnde daha önce kaydedilmemiștir. Khalazios Asia Minor'da şimdiye kadar iki yazıtta net bir şekilde belgelenmiştir'ㄹ: İlki Kyzikos'tan MÖ. I. yüzyıla tarihlenen bir yazıttır. Fakat bu yazıtta Zeus Khalazios olarak değil, Zeus Khalazios Sōzōn şeklinde karşımıza çıkmaktadır. Adak steli Bandırma yakınlarında Thrakia Kome'de bulunmuştur ve yazıtı, Thrakia Kome'lilerin Zeus Khalazios Sōzōn'a meyvelerin bol ürün vermesi ve zarar görmemesi için, çiftçilerin sağlığı ve selameti için adak sunduğunu açıklamaktadır². İkincisi ise Kili-

1 Bu iki örneğin dışında, Silifke Müzesi’ndeki taş eserlerle ilgili yayında bir eser “ $\Delta ı ̀$ XA $\Lambda$ A[” şeklinde okunmuştur. Epitheton, Khalazios olarak anlaşılmalıdır (SEG LXIII 1403).

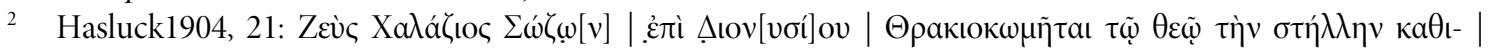

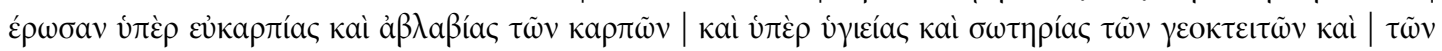

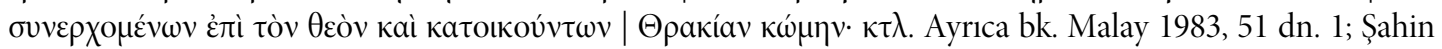
2001, 77 s.v. 'Zeus Khalazios'. 
kia’da, Anabarzos kentinin kuzeyinde Pekmezci Köyü’nde bulunmuştur. Bu adak taşı, ürünü doludan koruyan Zeus Halazeos’a adanmıștı³. Bilindiği üzere Zeus gökyüzü-hava olayları ile ilgili bir tanrıdır ve Zeus'e ilişkin farklı dönemlerde farklı yerlerde çok sayıda kült bilinmektedir. Dolayısıyla, şimdiye kadar Zeus ve epitheton'larıyla ilgili çalışmalar yapılmış, tespit edilen sıfatlar, eserlerin bulunduğu coğrafya ve dağılımıyla incelenerek değerlendirilmeye çalışılmıştır'.

Makaleye konu olan khalazios sıfatı, Hellence'de $\chi \dot{\alpha} \lambda a \zeta \alpha$ (= dolu yağmak) fiilinden türetilmiştir ${ }^{5}$. Dolayısıyla bu sıfat, hava olayları ile doğrudan ilişkili görünmektedir. Yağmurun/dolunun yağması, şimşek çakması gibi doğa olayları aynı zamanda toprağın bereketiyle de bağlantılı olduğu için, stelin geliş yerini tahmin etmek amacıyla bölgede tarımın ön planda olduğu alanları göz önünde bulundurmak gerekecektir. Küçük Asya'da bilhassa Phrygia'da çiftçiler için önemli olan Zeus Brontōn kültünde olduğu gibi, steldeki üzüm salkımının bağcılık ve şarapçllık faaliyetleri ile dolayısıyla da tarımla ilgili olması beklenmelidir. İhtiyaç duyulan yağmurun yağması, ekinlerin yetişmesi ve uygun hava koşullarında olgunlaşması için Zeus'e duyulan ihtiyaç, aynı zamanda dolunun yağmaması ve ekinin/üzümün zarar görmemesi için de gerekliydi'. Yukarıda Thrakia Kome’lilerin Zeus Khalazios Sōzōn'a adak yazıtında da belirtildiği gibi, bu yazıtta da ürünlerin bolluğu ve zarar görmemesi ön planda olmalıdır. Bu noktada Zeus'in Sōzōn olarak beraber ifade edilmesi de olağan görünmektedir. Hatta kurtarıcı/koruyucu bir kimlik taşıyan Zeus Sōtēr kültü de Zeus Sōzōn ile beraber değerlendirilebilir ${ }^{7}$. Bunların dışında ayrıca, kurtarıcı durumdaki tanrı, ilkel bir mantıkla, aynı zamanda fırtınaya sebebiyet de verendi. Fırtınaların, yağmurun, rüzgârın ve dolunun (ve diğer felaketlerin) insan kibirini ve suçlarını cezalandırmayı amaçlayan tanrısal bir öfkenin yansıması olduğu da düşünülmekteydi ${ }^{8}$.

Ülkemizin tarım ürünleri ihtiyacını büyük oranda karşılayan Antalya Bölgesinin antikçağda da bu açıdan zengin olduğu bilinmektedir. Şimdiye kadar bölgeden tarımla ilgili önemli veriler elde edilmiştir: Side'de Zeus Halonites (harman yerlerini koruyan tanrı) ve Demeter Anarsitike (huhubatı filizlendiren tanrıça) kültleri ön plandadır. Hatta hububat işlerinin ne kadar önemli olduğunu, kentte tahıl pazarındaki meselelerle ilgilenen bir memuriyet oluşturmalarından da anlayabiliriz? Bölge, kendi ihtiyacını karşılamanın ötesine geçerek tahıl ihraç etmekteydi. Örneğin, bir Pisidia kenti olan Pogla'da tahıl üretim miktarı iyi durumda olmalıydı ki, bu kentten Mısır’a tahıl gönderildiği bilinmektedir ${ }^{10}$. Hatta sadece Lykia'ya özgü olan sitometroumenoi adı altında buğday dağıtımı alan varlıklı kişiler bulundukları kentlerin politik, ekonomik ve sosyal yaşamına yön veriyordu ${ }^{11}$.

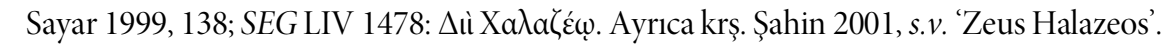

4 Cook I-III s.v.; Schwabl 1972, Şahin 2001, Akyürek-Şahin 2001, Karayaka 2007, Talloen 2015 yayınları örneklendirilebilir.

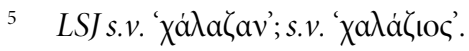

6 Akyürek-Şahin 2001, 167-168.

7 Bölgede Zeus Sōzōn kültü Tefenni'de (Weinreich 1927, s.v. 'Sozon' col. 1248), Pednelissos'ta (SEG II 717), Pisidia'da Ören Köyü Mevkii'nde (Weinreich 1927, s.v. 'Sozon’ col. 1248); Zeus Sōtēr ise Sillyon'da (SEG II 707), Kotenna'da (Bean - Mitford 1970, 30-31; yeni okuma: Adak 2018, 218-219), Neapolis’te (SEG LVII 1477), Oinoanda'da (Bean 1971, 18,35), Kibyra'da (Petersen - Luschan 1889, 247-248), Patara'da (TAM II 404), Kyaneai'da (Kolb - Zimmermann 1990, 123) kaydedilmiştir.

8 Nieto 2010, 571 dn. 53.

9 Nollé 1983. Krş. Akdoğu-Arca et al. 2011,291 ve dn. 24.

10 Bean 1960, 59-61 nr. 104. Krş. Akdoğu-Arca et al. 2011, 291 ve dn. 24.

11 Sitometroumenoi Andres, Oinoanda, Balboura, Patara, Boubon, Kadyanda, Korydalla, Arneai ve Neisa'da tespit
} 
Lykia'da dağlık kesimlerin dışındaki araziler tarım için değerlendirilmekteydi, Elmalı ve Demre Ovaları tahıl üretiminde önemli bir yerdeydi ${ }^{12}$.

Tahıl dışında, şarap ve zeytin kültürü de bölgede yaygındı. Örneğin, Perge'de MS. I. yüzyılın ilk yarısına tarihlenen bir yazıtta Perge Artemis Tapınağı yakınlarında bir mevkide, üzüm bağlarının yer aldığı düşünülmektedir ${ }^{13}$. Ayrıca Pamphylia' da, ismini Skybela denilen bir yerden alan Skybelitis üzüm türünün yetiştiği kaydedilmiştir ${ }^{14}$. Yapılan çalışmalarda sadece Kyaneai kentinde elli adet şarap ve zeytinyağı işliği tespit edilmiştir. Balboura yakınlarında 1600 metre yükseklikte, işlik olduğu-

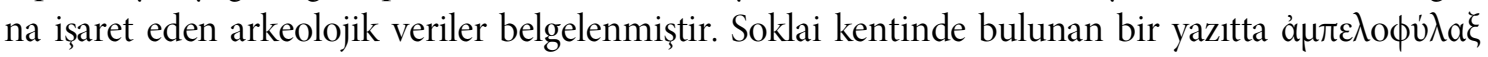
yani bağ koruma işini üstlenen bir memuriyet ifadesi, bağlara gösterilen özen ve öneme işaret etmektedir ${ }^{15}$. Homeros'tan, Ksanthos Vadisi’nde üzüm ve buğdayın yetiştiği öğrenilmektedir. Kadyanda kentinin adı Likçe'de "tahılı bol", Oinoanda kentinin adı ise Hititçe Wiyanawanda olarak "bağı bol" anlamına gelmektedir ${ }^{16}$. Hatta Kadyanda’nın günümüz adının Üzümlü olması, antikçağ bağcılık geleneğinin bir uzantısı olmalıdır. Ürünleri yetiştirme yaygınlığı, bölgenin tarıma elverişli alanlarının geniş olmasının yanı sıra, aynı zamanda uygun bir iklime de sahip olmasıyla açıklanabilir. Khalazios sıfatının doğrudan yağışlarla/doluyla ilgili olması yağış verilerini göz önünde bulundurmayı gerektirir. H. Hellenkemper ve F. Hild, Antalya Bölgesi yağışlarını şöyle açılklamaktadır: "Kıyı kesimlerinde yıllık yağış 600 mm'nin altına düșmez. En az yağış alan bölge, Fethiye Körfezi'nden Kekova'ya kadar olan sahil kısmıdır. Lykia’nın doğu kıylları ve Pamphylia kıyıları Toroslara kadar yıllık 1000 ile $2000 \mathrm{~mm}$ arasında; Torosların ardındaki yaylalar ise 600 ile $1000 \mathrm{~mm}$ arasında yağış alır. Elmalida, Kabalitis'te 500-600 mm, Bozova'da ise 400-500 mm yağıs alır" ${ }^{\prime \prime}$. Bu ifadelerden, kıyllarda yağışın bol olduğu, iç kesimlerde yüksek alanlarda ise bu oranın düştüğü anlaşılmaktadır. Bağcılık ve şarap üretimi için yıllık 500-600 mm yağışın yeterli oluşu, iç kesimlerdeki üretim yoğunluk nedeninin daha iyi anlaşılmasını sağlayabilir.

Tarım faaliyetlerinin yoğunluğu ve verimi, doğal olarak ekonomik boyutunu da beraberinde getirmektedir. Tarımla ilgilenenler ve antik yaşamdaki yerleri için söylenebilecekler azımsanmayacak kadar fazladır. Esasen bölgede arazi zengini olarak nitelendirebileceğimiz aile sayısı da fazla görünmektedir $^{18}$. Böyle ailelerin arazilerini nasıl değerlendirdiği sorusunu, Oinoanda’nın önde gelen Licinnii soyundan Licinnius Musaeus' in onurlandırıldığı bir yazıt yanıtlayabilir. Yazıtta Pinara'lı kiracı Zosimos, Licinnius Musaeus'i onurlandırmaktadır. Yazıttan, Musaeus'in Pinara teritoryumunda

edilmiştir. Bu kişilerin faaliyetleri hakkında ayrıntılı bilgi için bk. Akdoğu-Arca 2016.

12 Hellenkemper - Hild 2004, 158.

13 IPerge I 66.

14 Brandt 1992, $130 \mathrm{dn} .1134$.

15 Hellenkemper - Hild 2004, 162.

16 Akdoğu-Arca 2016, 124.

17 Hellenkemper - Hild 2004, 93-94.

18 Örneğin, bölgenin en önde gelen euergetes'lerinden Opramoas' ın zenginliği, uçsuz bucaksız tarım arazilerinden kaynaklanmaktadır. Günümüzde de Antalya’nın sebze ve meyve ihtiyacını büyük oranda sağlayan Kumluca Ovası tarımı antikçağ da da oldukça faal olmalıydı (Akdoğu-Arca 2002). Bir başka örnek, Sidyma'dan Eukarpoi'dur: Bu aileden M. Aur. Eukarpos, Kragos çevresindeki bütün topraklarını vasiyet yoluyla kente bırakmıştır (TAM II 190). Bu şahısla aynı ismi taşıyan babası M. Aurelius Eukarpos Sidyma'da Ispada adı verilen topraklarını Yaşlılar Meclisi'ne bırakmıştır (TAM II 188). Patara’nın önde gelen ailelerinden Claudii üyesi Claudia Anassa’nın eşi Tib. Cl. Eudemos’un Halias denen yerde arazisi olduğu anlaşılmaktadır (TAM II 429). 
toprakları olduğu ve bunları kiraya verdiği anlaşılmaktadır ${ }^{19}$. Örnekler arttırılabilir: Oinoanda’nın önde gelen aileleri esasen Seki Ovası'ndaki tarım arazilerinin çoğuna sahipti ${ }^{20}$. Örneğin, bu kentin önde gelen zenginlerinden Demosthenes, gelirini sahip olduğu arazilere borçluydu ve arazileri kiraya vererek topraklarını işletiyordu ${ }^{21}$. Ormeleis'te, Alassos'ta, Perge'ye bağlı Lyrboton Kome'de özel şahıs arazileri ve tarımla uğraşıldığı bilinmekteydi' ${ }^{22}$. Perge'nin en önde gelen ailelerinden Plancii, Antalya'nın $60 \mathrm{~km}$ kuzeybatısında Andeda'da topraklara sahipti ${ }^{23}$.

Sonuç olarak, tarım, Antalya Bölgesi için her daim önemli bir yer teşkil etmiştir. Dolayısıyla, uygun hava koşulları, tarımı doğrudan etkileyen başlıca unsur olmuştur. Bu nedenle, Zeus kültünün de bölgede yeri son derece önemli olmalıdır. Günümüzde olduğu gibi, yağmurun aşırı yağışı, don, dolunun miktarı ve şiddeti gibi doğa olayları, ürünleri mutlaka olumsuz yönde etkiliyor olmalıydı. Bu şartlar doğrultusunda, antikçağ çiftçisinin Zeus'le bağlantısının daimi olması beklenir. Yazıtta khalazios sıfatının yani bilhassa dolu yağması ile ilgili bir epitheton'un varlığı, muhtemelen ya yaşanmış olumsuz koşullardan artık kurtulma isteği ya da gelecekte bunun yaşanmaması için bir adım olarak önerilebilir. Bu amaçla Dēmētrios, Zeus rahibi olarak girişimde bulunmuş olabilir. Taşın buluntu yeri hakkında kesin bir öneride bulunmak zordur. Yazıtta adı geçen isimlerden Zöilos ${ }^{24}$ Lykia, Pamphylia, Kabalitis ve Pisidia'da kaydedilmiştir. Sillyeus ismi sık karşılaşılan bir isim olmamakla birlikte Perge'de görülmüştür ${ }^{25}$. İsimlerin yayılım alanı üzerinden tahmin yürütmek yine de olası görünmemektedir. Ayrıca, Müze araştırmaciları stelin taş yapısının daha ziyade Korkuteli taraflarından gelen eserlere benzediğini sözlü olarak ifade etmişlerdir. Bütün bu verilere ek olarak, Pisidia'dan iki örneği de göz önünde bulundurmak gerekecektir: Bu örneklerden ilki, Isparta Müzesi'nde korunan ve Çürüş’ten getirilmiş bir sunaktır (env. no. 1.3.94). Sunağın ön yüzünde Zeus büstü, sağ yan yüzünde bereket boynuzundan sarkan üzüm ve meyveler, sol yan yüzünde üzüm salkımı ve arka yüzünde ise buğday demeti ișlenmiştir. Yazıtında Rhodōn'un, taşı Zeus'e adak olarak sunduğu ifade edilmektedir ${ }^{26}$. İkinci örnek ise, Burdur civarında bulunarak Burdur Müzesi’ne getirilen bir sunaktır. Zeus Karpophoros'a adanan sunakta buğday demeti işlenmiştir ${ }^{27}$. "Ürünü taşıyan tanrı" anlamına gelen Zeus Karpophoros'un kültü Batı Pisidia'da, Sagalassos ile Kibyra arasında belgelenmiştir ${ }^{28}$. Zeus ile ilgili üzüm ve buğday motiflerinin sunaklar üzerinde Batı Pisidia Bölgesi'nde görülmesi/yoğunlaşması, burada tanıtılan sunağın da o coğrafyaya ait olabileceğini düşündürmektedir. Taş yapısının Korkuteli civarından gelen eserlere benzemesi, bu tahminimizi güçlendirmektedir.

\footnotetext{
IGR III 576 .

Ras 1995, 35.

Wörrle 1988, 4 str. 14-15, 6 str. 20 ve 28.

Hellenkemper - Hild 2004, 158.

Mitchell 1974, 33; Hellenkemper - Hild 2004, 434 s.v. 'Andida'.

$L G P N V^{\mathrm{B}-\mathrm{C}}$ s.v. 'Zwï̀oc'.

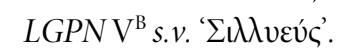

Özlem-Aytaçlar 2010, 223-224 no. 1. Ayrıca, Talloen 2015, 249 dn. 631.

Horsley 2007, 112 no. 190.

28 Talloen 2015, 249.
} 
Adak 2018

Akdoğu-Arca 2002

Akdoğu-Arca 2016

Akdoğu-Arca et al 2011

Akyürek-Şahin 2001

Özlem-Aytaçlar 2010

Bean - Mitford 1970

Bean 1960

Bean 1971

Brandt 1992

Cook

Hasluck 1904

Heberdey - Kalinka 1897

Hellenkemper - Hild 2004

Horsley 2007

$I G R$

IPerge I

Karayaka 2007

Kolb - Zimmermann 1990

$L G P N V^{\mathrm{B}}$

$L G P N V^{\mathrm{C}}$

Malay 1983

Mitchell 1974

Nieto 2010

\section{Nuray GÖKALP ÖZDİL}

\section{BİBLIYYGRAFYA}

M. Adak, "Die Melas-Brücke bei Kotenna und die Familie des Stanamoas". Adalya 21 (2018) 211-228.

E. N. Akdoğu-Arca, "Lykia'lı Bir Euergetes Opramoas”. Eds. S. Şahin - M. Adak, Likya İncelemeleri I. İstanbul (2002) 79-90.

E. N. Akdoğu Arca, "Lykia’ya Özgü Bir Kavram Olarak Sitometroumenoi Andres'i Plinius'un 116/117. Mektupları Işı̆̆ı̀nda Yeniden Değerlendirme”. Adalya 19(2016) 115-132.

E. N. Akdoğu-Arca - N. Gökalp - N. Tüner-Önen, "Pamphylia Bölgesi'nin Mısır ve Kıbrıs ile Olan İlişkileri”. Olba 19 (2011) 287-312.

N. E. Akyürek Şahin, "Büyük Çiftçi Tanrısı Zeus Bronton. Arkeolojik ve Epigrafik Belgelerle Phrygia’da Bir Zeus Kültü”. Olba 4 (2001) 163-182.

P. Özlem-Aytaçlar, "Some Unpublished Inscriptions in the Isparta Museum”. Adalya 13 (2010) 223-242.

G. Bean - T. B. E. Mitford, Journeys in Rough Cilicia 1964-1968. Wien 1970.

G. Bean, "Notes and Inscriptions from Pisidia II". AS 10 (1960) 43-82.

G. Bean, Journeys in Northern Lycia 1965-1967. Wien 1971.

H. Brandt, Gesellschaft und Wirtschaft Pamphyliens und Pisidiens im Altertum, AMS 7. Bonn 1992.

A. B. Cook, Zeus: A Study in Ancient Religion (Vol. I-III). Cambridge 1914, London 1925, 1940.

F. W. Hasluck, "Unpublished Inscriptions from the Cyzicus Neighbourhood". JHS 24 (1904) 20-40.

R. Heberdey - E. Kalinka, Bericht über zwei Reisen im südwestlichen Kleinasien. Wien 1897.

H. Hellenkemper - F. Hild, Tabula Imperii Byzantini 8: Lykien und Pamphylien, Wien 2004.

G. H. R. Horsley, The Greek and Latin Inscriptions in the Burdur Archaeological Museum. Ankara 2007.

R. Cagnat et al., Inscriptiones Graecae ad Res Romanas pertinentes I-IV. Paris 1906-1927.

S. Şahin, Die Inschriften von Perge I. Bonn 1999.

N. Karayaka, Hellenistikve Roma Döneminde Pisidia Tanrıları. İstanbul 2007.

F. Kolb - M. Zimmermann, "Neue Inschriften aus Kyaneai und Umgebung”. EA 16 (1990) 115-138.

Eds. J. S. Balzat, R. W. V. Catling - É. Chiricat, A Lexicon of Greek Personal Names: Coastal Asia Minor, vol. VB. Oxford 2013.

Eds. J. S. Balzat, R. W. V. Catling - É. Chiricat - T. Corsten, A Lexicon of Greek Personal Names: Inland Asia Minor, vol. VC. Oxford 2018.

H. Malay, "Batı Anadolu'nun Antik Çağdaki Ekonomik Durumu”. Sanat Tarihi Dergisi 2 (1983) 50-61.

S. Mitchell, “The Plancii in Asia Minor”. JRS 64 (1974) 27-39.

F. J. F. Nieto, "A Visigothic Charm from Asturias and the Classical Tradition of Phylacteries against Hail”. Eds. R. L. Gordon - F. M. Simon, Magical Practice in the Latin West: Papers from the International Conference held at the University of Zaragoza 30 Sept.- 1 Oct. 2005. Leiden (2010) 551-599. 
Nollé 1983

Petersen - Luschan 1889

Ras 1995

Sayar 1999

Schwabl 1972

SEG

Şahin 2001

Talloen 2015

TAM II

Weinreich 1927

Wörrle 1988
J. Nollé, “Zum Landbau von Side”. EA 1 (1983) 119-129.

E. Petersen - F. von Luschan, Reisen in Lykien, Milyas und Kibyratis (Reisen im sudwestlichen Kleinasien II). Vienna 1889.

M. Ras, "Oinoanda in Lycia, The Elite and Economy in the Roman Empire". Lykia 2 (1995) 22-38.

M. H. Sayar, "Kilikya' da Tanrllar ve Kültler". Olba 2 (1999) 131-154.

H. Schwabl, s.v. 'Zeus'. REX/A (1972) 253-376.

Supplementum Epigraphicum Graecum. Leiden 1923 vd. (vols. 1-25); Alphen 1979-1980 (vols. 26-27); Amsterdam 1982 vd. (vols. 28 vd.)

N. Şahin, Zeus'un Anadolu Kültleri. İstanbul 2001.

P. Talloen, Cult in Pisidia. Religious Practice in Southwestern AsiaMinor from Alexander the Great to the Rise of Christianity. Turnhout 2015.

E. Kalinka, Tituli Asiae Minoris, II: Tituli Lyciae linguis Graeca et Latina conscripti. Wien 1920 (fasc. I); 1930 (fasc. II); 1944 (fasc. III).

O. Weinreich, s.v. 'Sozon'. RE III/A1 (1927) 1248-1255.

M. Wörrle, Stadt und Fest im kaiserzeitlichen Kleinasien. München 1988. 
